\title{
Acyclovir and trichostatin A modulate EHV-1 replication in murine neurons in vitro")
}

\author{
ANNA GOLKE, JOANNA CYMERYS, ANNA TUCHOLSKA, ANNA CHMIELEWSKA, \\ ANNA SŁOŃSKA*, MARCIN CHODKOWSKI, IZABELA SERAFIŃSKA, \\ JOANNA BRZEZICKA, MARCIN W. BAŃBURA
}

\begin{abstract}
Division of Microbiology, Department of Preclinical Sciences, Faculty of Veterinary Medicine, Warsaw University of Life Sciences, Ciszewskiego 8, 02-786 Warsaw, Poland

*Division of Physiology, Department of Physiological Sciences, Faculty of Veterinary Medicine, Warsaw University of Life Sciences, Nowoursynowska 159, 02-776 Warsaw, Poland
\end{abstract}

Golke A., Cymerys J., Tucholska A., Chmielewska A., Słońska A., Chodkowski M., Serafińska I., Brzezicka J., Bańbura M. W.

Acyclovir and trichostatin A modulate EHV-1 replication in murine neurons in vitro

Summary

Equine herpesvirus type 1 (EHV-1) is a major viral pathogen of horses, causing respiratory disease, abortions, and equine herpes myeloencephalopathy (EHM). Like other alphaherpesviruses, EHV-1 establishes latency in neurons, but mechanisms involved in this process are still elusive. In the present study, we used antiviral drug acyclovir (ACV) to completely suppress EHV-1 replication in primary murine neuron culture. Trichostatin A (TSA), a known chemical reactivator of other herpesviruses, was used to stimulate productive EHV-1 infection. Moreover, gene expression of some cytokines was simultaneously evaluated, in order to check, whether the maintenance conditions of such a model may influence host cell response. Changes observed in IFN- $\alpha$, IFN- $\beta$, and IL-10 mRNA gene expression depended on the EHV-1 strain. Although infection with either of the two EHV-1 strains investigated led to in an increase in type I IFNs gene expression, only the neuropathogenic strain caused a decrease in anti-inflammatory IL-10 gene expression. Unlike EHV-1 infection, the addition of neither ACV nor TSA caused significant changes in the expression of the above genes. We may therefore conclude that the in vitro model presented in the study is suitable for detailed investigation of the host cell-virus relationship on the molecular level.

Keywords: neurons, EHV-1, acyclovir, trichostatin A, replication cycle

Equine herpesvirus type $1(\mathrm{EHV}-1)$ is one of the most important viral pathogens of horses worldwide (2). It may cause respiratory disease, sporadic or epizootic abortions, or, recently more often, neurological disease known as equine herpesvirus myeloencephalopathy (EHM), which may be life-threatening and results in significant economic losses to the equine industry (1, $13,15,18,19)$.

It has been suggested that a single-nucleotide polymorphism in the EHV-1 DNA polymerase gene, which leads to amino acid variation (N752/D752), may be associated with outbreaks of $\operatorname{EHM}(3,11,13)$. D752 strains of EHV-1, which are statistically more often isolated from cases of EHM, were called neuropathogenic strains. However, it is worth mentioning that all

This work was supported by Early Stage Researcher grant no. UMO-KNOW2015/SGGW/ESR2/01/1 within the consortium Leading National Research Centre, Scientific Consortium "Healthy Animal - Safe Food".
EHV-1 strains show neurotropism and are capable of establishing latency in peripheral neurons. Moreover, EHV-1 may also establish latency in leukocytes (10). The main role of latency is to maintain the viral genome for a long time inside host cells, at the same time avoiding the immune response. On the other hand, the virus may reactivate and start productive replication at any time, especially during stress, which leads to the dissemination of progeny virions (17).

The current approach to the control of EHV-1 infections is based on biosecurity measures and vaccination, but it is not sufficient. Immunity after infection or vaccination is usually incomplete and short-lived, and once latency has been established, the virus cannot be eliminated from host cells. Although some progress has been made in understanding the adaptive immunity to EHV-1, innate immunity remains poorly characterized, despite the fact that it is critically important for induc- 
tion of adaptive immune responses (12). Moreover, the exact role of innate immunity in the maintenance of latent infection and reactivation is still elusive. Unfortunately, despite years of investigation, our understanding of the molecular mechanisms underlying the establishment of EHV-1 latency and reactivation remains incomplete. A detailed study of interactions between EHV-1 and host cells at the molecular level would be possible using a pure population of neurons. Such a model would also help avoid many confounding issues associated with studying latency and reactivation in vivo that can potentially obscure virus-cell interactions $(8,9,20)$.

In the present study, the main focus was on creating an appropriate in vitro model in which the complete suppression, as well as the restoration, of EHV-1 replication will be possible. In addition, our goal was to create a model in which the conditions of its maintenance will not interfere with processes occurring in the host cell, such as the innate immune response against viral infection. We also aimed to answer the question whether such a model would be suitable to investigate replication kinetics of different strains of EHV-1.

\section{Material and methods}

Virus strains. Two strains of EHV-1 from the virus collection of the Virology Laboratory of the Warsaw University of Life Sciences - SGGW were used: the Jan-E non-neuropathogenic strain, which was confirmed by PCRRFLP (21), and the 26 strain, isolated in 2004 in Hungary, whose neuropathogenicity was confirmed by the PriProET technique (16).

Cell cultures. Balb/c $\left(\mathrm{H}-2^{\mathrm{d}}\right)$ mice, genetically susceptible to EHV-1 infection, were used to establish primary cultures of murine neurons as described previously $(6,9)$. For this purpose, cells isolated from fetal brains were cultured in B-27 Neuron Plating Medium containing B-27 supplement, $200 \mathrm{mM}$ of glutamine, $10 \mathrm{mM}$ of glutamate, penicillin/ streptomycin antibiotics, $5 \%$ of fetal and $5 \%$ equine serum. Neuronal cultures were maintained at $37^{\circ} \mathrm{C}$ with $5 \% \mathrm{CO}_{2}$. After five days, the medium was replaced with Neuron Feeding Medium without glutamate and maintained for the next 6 days before further manipulations. All animals were handled according to Polish and European Animal Care and Use regulations. All procedures involving live animals were approved by a Local Ethics Committee (agreement No. 25/2012).

Cell culture infection. Cell cultures were infected with either the Jan-E or 26 strain of EHV-1 at MOI $=0.3$ for $1 \mathrm{~h}$ at $37^{\circ} \mathrm{C}$, and after incubation the inoculum was replaced with a fresh culture medium. For each EHV-1 strain, six variants of the experiment were conducted.

Cell cultures were infected with EHV-1 for 1, 7, and 14 days without acyclovir (ACV) or trichostatin A (TSA). Simultaneously, cells were infected in the presence of ACV $(128 \mu \mathrm{g} / \mathrm{ml})$ for 7 days. Additionally, in the cell cultures which had been infected in the presence of ACV, the culture medium was removed after 7 days of incubation and replaced with a fresh one without $\mathrm{ACV}$, but with the addition of TSA $(100 \mu \mathrm{M})$, for another 7 days. The removal of ACV was graphically represented as ACVx. Moreover, during the evaluation of relative gene expression, cells treated only with ACV and TSA for 1 day served as a control. The ACV concentration that effectively inhibits EHV-1 replication was established previously on the basis of the evaluation of cytopathic effect and the quantification of viral DNA levels by real-time PCR in an equine dermal (ED) cell line (data not shown), as well as our previous study concerning the replication of herpesviruses in primary murine neurons (5).

RNA extraction and reverse transcription assay. Total RNA was obtained from $1 \times 10^{6}$ cultured murine neurons, according to the manufacturer's instructions using a Total RNA isolation kit (A\&A Biotechnology). RNA was quantified by absorbance at $260 \mathrm{~nm}$. The cDNA was synthesized from $1 \mu \mathrm{g}$ of total RNA using the MMLV-reverse transcriptase and oligo (dT)18 primer (Thermo Scientific) for $1 \mathrm{~h}$ at $37^{\circ} \mathrm{C}$. Reverse transcription was preceded by the removal of genomic DNA with dsDNase for $2 \mathrm{~min}$ at $37^{\circ} \mathrm{C}$ (Thermo Scientific).

Gene expression analysis. For the real-time PCR analysis of relative gene expression, primers were designed and optimized using the LightCycler Probe Design Software 2.0, and their sequences were as follows: GAPDH F 5'GCTGAATGGGAAGCTC3', R 5'CTCAGTGTAGCCCAGGA3'; IFN- $\alpha$ F 5'GGCTCTGCCTGTTTCCTTA3', R 5'TCCAAAGTCATTTCTGTCCTTCA3'; IFN- $\beta$ F 5'GAGACAAACCTGGAGGAAATAA3', R 5'TTCCTGAGCATTTCCGC3'; IL-10 F 5'GCTCCAAGAGAAAGGTGT3', R 5'TCTCCAATTTATGTCCTAGAGTCTAGTA3'. Real-time PCR was performed in a LightCycler 2.0 instrument (Roche Diagnostics) using LightCycler FastStart DNA Master SYBR Green I (Roche Diagnostics), forward and reverse primers for each target of interest, and $2 \mu \mathrm{l}$ of the cDNA. The PCR protocol consisted of initial incubation for $10 \mathrm{~min}$ at $95^{\circ} \mathrm{C}$, followed by PCR cycling using a three-step cycle: denaturation at $95^{\circ} \mathrm{C}$ for $10 \mathrm{sec}$, annealing at $58^{\circ} \mathrm{C}$ for $5 \mathrm{sec}$, and elongation at $72^{\circ} \mathrm{C}$ for $6 \mathrm{sec}$, for a total of 45 cycles. The melt of the PCR product was performed from 55 to $95^{\circ} \mathrm{C}$. The relative expression of target genes was analyzed using the $\Delta \Delta \mathrm{Ct}$ method. The amount of specific mRNA was normalized to GAPDH mRNA levels. The final PCR results represent three separate experiments.

Quantification of viral DNA. The quantity of the EHV-1 DNA was estimated using quantitative real-time PCR (qPCR) with the fluorescent TaqMan probe. Sequences of primers and probe, complementary to the EHV-1 gB gene, were as follows: forward-5'CACGTCTTTAGCGGTGAT3', reverse-5'CAAGCTCGT TCAGGTACAG 3', probe-FAMTGCATTCAGACCTATGCTCTCCAAC-BHQ. Viral DNA was isolated separately from cells and the cell culture medium using High Pure Viral Nucleic Acid Kit ${ }^{\mathbb{B}}$ (Roche Diagnostics) according to the manufacturer's instructions. Real-time PCR tests were run on a LightCycler 2.0 instrument (Roche Diagnostics). The reaction mixture was prepared using TaqMan Master Kit ${ }^{\circledR}$ (Roche Diagnostics). Each amplification reaction included positive calibrators in the range of $10^{2}-10^{6}$ copies $/ \mathrm{mL}$ and a negative control. Fluorescence levels were measured at $560 \mathrm{~nm}$ wavelength, and 
a threshold cycle $(\mathrm{Ct})$ value for each sample was calculated. $\mathrm{Ct}$ values of EHV-1 calibrators were the basis for standard curves, and the copy numbers were calculated automatically by software. Calibrators were prepared using a plasmid construct which was developed by cloning a fragment of the EHV-1 gB gene (328 bp) into SmaI digested pBluescript II SK(-) (Epoch LifeScience, USA). The concentration of obtained amplicon DNA was determined spectrophotometrically by absorbance of UV light at 260 and $280 \mathrm{~nm}$. The limit of detection (LOD) was determined by the analysis of serial decimal dilutions of amplicon DNA in the range of $10^{1}-10^{6}$ copies. Each dilution was prepared and analyzed in six independent replications. Probit analysis was used to calculate the LOD concentration (4). The LOD of the qPCR assay, established at the level of 227 copies per mL, was adopted for this study as the cut-off value.

Statistical analysis. All experiments were performed in triplicate, and each analysis was repeated at least twice. Differences in mean values were analyzed by Student's t-test. Statistical differences were interpreted as significant at $\mathrm{P} \leq 0.05(*)$ and $\mathrm{P} \leq 0.01(* *)$, and not significant at $\mathrm{P}>0.05$.

\section{Results and discussion}

In order to evaluate the number of EHV-1 DNA copies in cells and the cell culture medium, quantitative real-time PCR was applied. No significant differences were observed in the replication kinetics of the Jan-E and 26 strains of EHV-1. In both cases, 1 day post infection (p.i.) a higher number of viral DNA copies were detected in murine neurons than in the cell culture medium. In the case of the Jan-E strain, it was $7.7 \times 10^{4} \pm 6.5 \times 10^{3}$ in cells and $2.27 \times 10^{4} \pm 3.2 \times 10^{3}$ in the cell culture medium (Fig. $1 \mathrm{~A}$ ), and in the case of the 26 strain, $4.7 \times 10^{4} \pm 1.1 \times 10^{3}$ in cells and $3.78 \times 10^{4} \pm 1.02 \times 10^{3}$ in the medium (Fig. $1 \mathrm{~B}$ ). After 7 days of infection, a significant decrease in the number of EHV-1 DNA copies was detected, and after 7 days of infection in the presence of ACV, no viral DNA was found either in cells or in the cell culture medium. However, 7 days after removal of ACV (ACVx), viral DNA was detectable both in cells and in the cell culture medium in comparable numbers. It was also observed in cell cultures in which ACV removal was accompanied by the addition of TSA (ACV x TSA) (Fig. $1 \mathrm{~A}, \mathrm{~B}$ ).

In both cases, the number of EHV-1 DNA copies was statistically significantly higher than in the cell cultures which were infected in absence of ACV for 15 days. Interestingly, DNA copy numbers in cell cultures in which ACV had been removed were slightly lower, but comparable to those in which the removal of ACV was accompanied by the addition of TSA.

Moreover, the evaluation of the relative mRNA gene expression of IFN- $\alpha$, IFN- $\beta$ and IL-10 was performed by real-time PCR. All results are presented as a fold change of expression in comparison to uninfected controls untreated with ACV or TSA. Aside from statistical significance, results indicating a fold change of

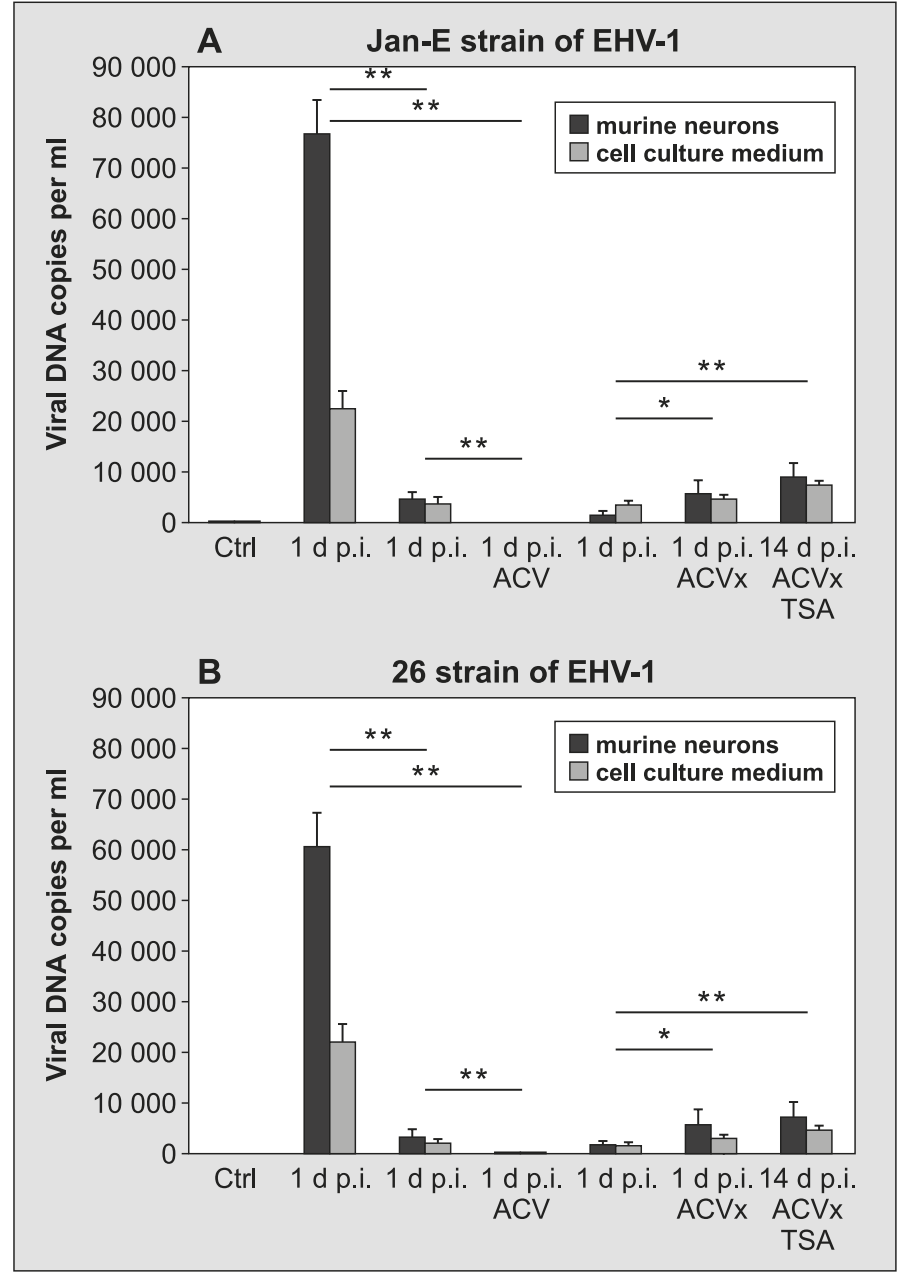

Fig. 1. Real-time PCR quantification of viral DNA. The number of viral $\mathrm{gB}$ gene copies/ml of non-neuropathogenic Jan-E strain (A) and neuropathogenic 26 strain (B) in murine neurons and cell culture medium

Explanations: * significant at $\mathrm{P} \leq 0.05 ; * * \mathrm{P} \leq 0.01$

expression lower than 2 in comparison to control were considered insignificant. In this experiment, uninfected primary murine neurons treated with ACV or TSA for 1 day were also included. One-day period of treatment with ACV or TSA was chosen deliberately, as changes in cytokine expression usually occur shortly after any change in the cell environment and may interfere with a viral infection.

The results show that changes in IFN- $\alpha$, IFN- $\beta$, and IL-10 mRNA gene expression depended on the EHV-1 strain used for infection, but no significant changes in the expression of these genes were detected in cells treated with ACV or TSA. One day after infection with the Jan-E strain, we observed 4.1 and 3 fold increases $(\mathrm{P}<0.05)$ in IFN- $\alpha$ and IFN- $\beta$ mRNA gene expression, respectively. No significant change in expression of the IL-10 gene occurred (Fig. $2 \mathrm{~A}, \mathrm{C}, \mathrm{E}$ ). In the case of primary murine neurons infected with the 26 strain of EHV-1, $6.6(\mathrm{P}<0.01)$ and 3.6 fold increases $(\mathrm{P}<0.05)$ in IFN- $\alpha$ and IFN- $\beta$ gene expression, respectively, were observed. Moreover, a 2.2 fold decrease in IL-10 gene expression was observed, but it was statistically insignificant (Fig. 2. B, D, F). No significant changes 


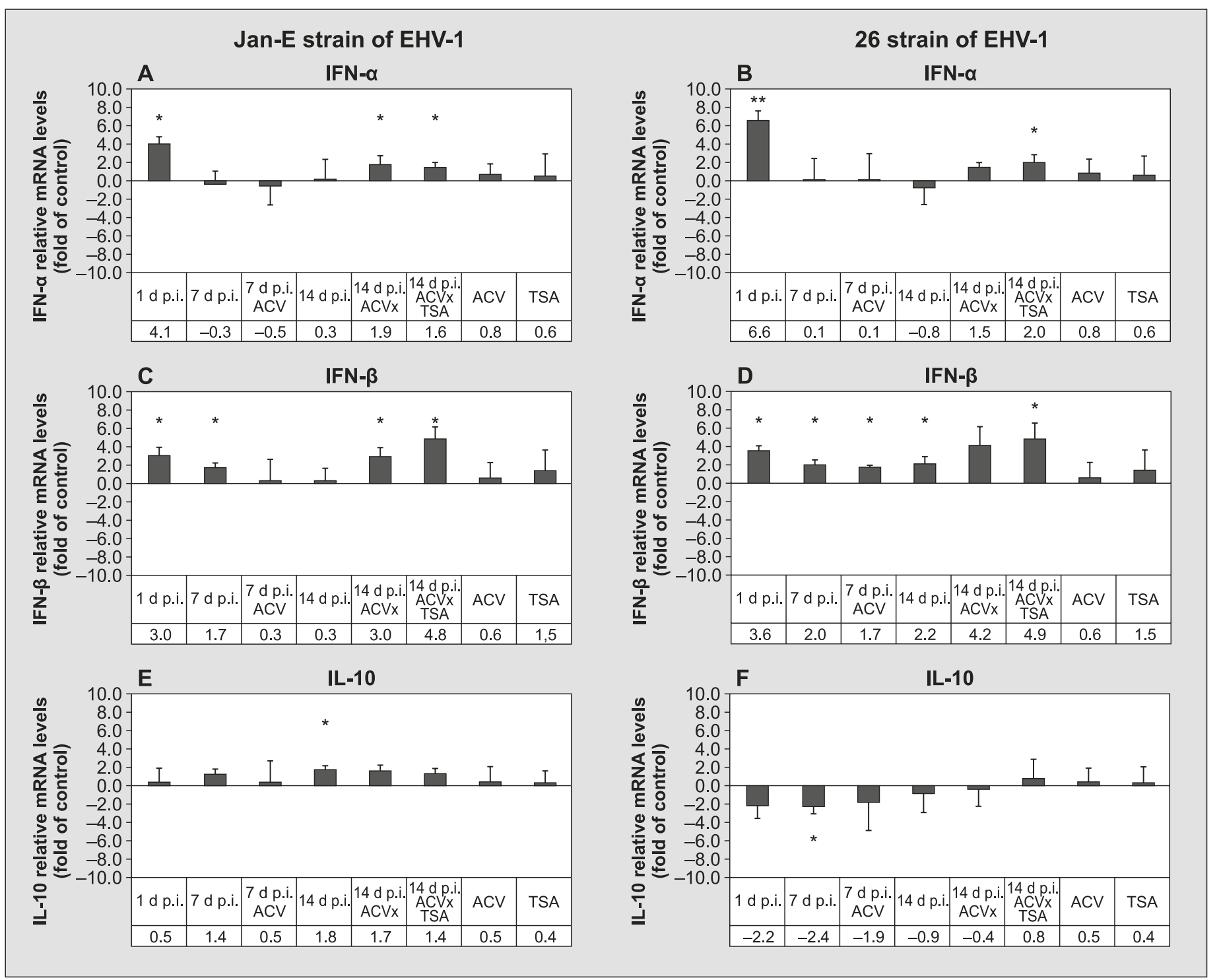

Fig. 2. Relative mRNA gene expression of IFN- $\alpha$, IFN- $\beta$, and IL-10 after infection with non-neuropathogenic Jan-E strain $(\mathrm{A}, \mathrm{C}, \mathrm{E})$ and neuropathogenic 26 strain $(\mathrm{B}, \mathrm{D}, \mathrm{F})$ in primary murine neurons

Explanations: Results are presented as a fold change in relation to uninfected control $(0) ; *$ significant at $\mathrm{P} \leq 0.05 ; * * \mathrm{P} \leq 0.01$

in the expression of IFN- $\alpha$ and IFN- $\beta$ genes were observed $7 \mathrm{~d}$ p.i. and $14 \mathrm{~d}$ p.i. with or without the addition of ACV, except in the case of infection with the 26 strain without $\mathrm{ACV}$, when 2 fold and 2.2 fold increases $(\mathrm{P}<0.01)$ in the IFN- $\beta$ gene occurred 7 and $14 \mathrm{~d}$ p.i., respectively. Interestingly, $7 \mathrm{~d}$ p.i. in the presence of ACV, IFN- $\beta$ expression was comparable to control. After ACV removal, in neurons infected with both EHV-1 strains, the increase in IFN- $\alpha$ and IFN- $\beta$ gene expression was observed again. Moreover, 1 and $7 \mathrm{~d}$ p.i. with the 26 strain a decrease in IL-10 gene expression was observed.

In the present study, we aimed to design an in vitro model in which productive infection with EHV-1 can by completely suppressed and activated again under controlled conditions. For this purpose, we infected primary murine neurons with neuropathogenic and non-neuropathogenic EHV-1 strains in the presence or absence of the antiviral drug ACV suppressing productive infection. Trichostatin A (TSA) was used to stimulate productive infection after ACV removal, as it is a known chemical reactivator of HSV-1 (14). No significant differences in replication kinetics were shown between Jan-E and 26 strains, which was also demonstrated previously (7).

It was shown previously that the N752 (non-neuropathogenic) strain of EHV-1 did not cause neurological signs in the natural host, but infection with the D752 (neuropathogenic) mutant resulted in inflammation of the central nervous system and ataxia, which was also correlated with significantly increased levels of viremia. It was also shown that the magnitude of virus shedding replication kinetics in fibroblasts and epithelial cells was similar for both N752 and D752 strains (11). However, since the neuropathogenicity of particular EHV-1 strains is rather associated with the increased infection of endothelial cells in small blood vessels within the CNS, the replication rate of different EHV-1 strains in neurons may not be connected with neuropathogenicity at all (7). 
Regardless of the strain used for infection, we succeeded in suppressing EHV-1 replication in primary murine neurons, which was confirmed by the number of viral DNA copies evaluated by quantitative real-time PCR. Using the same method, we confirmed that EHV-1 replication can be reinstated by the simple removal of ACV from the cell culture or by the addition of TSA. It was observed that the numbers of EHV-1 DNA copies in cultures from which ACV was removed were comparable to those in cultures to which TSA was added. This may suggest that TSA addition is not necessary to restore EHV-1 replication. However, it seems particularly important that neither ACV nor TSA caused any significant changes in gene expression of IFN- $\alpha$, IFN- $\beta$, and IL-10. It is also important to mention that after infection with the 26 strain (neuropathogenic), we observed a decreased expression of IL-10 (Fig. 2 F). It was previously shown that in equine peripheral blood mononuclear cells (PBMC) another neuropathogenic strain of EHV-1 (Ab4) reduced IL-10 production, and it was suggested that this mechanism may contribute to increased local inflammation leading to the occurrence of neurological manifestations (22).

In conclusion, since we were able to completely inhibit EHV-1 replication, and since the addition of ACV or TSA did not cause statistically significant changes in the expression of the abovementioned genes, it is our belief that the in vitro model presented here may be successfully used to study interactions between EHV-1 and its host cells at the molecular level.

\section{References}

1. Allen G. P.: Risk factors for development of neurologic disease after experimental exposure to equine herpesvirus-1 in horses. Am. J. Vet. Res. 2008, 69, 1595-1600.

2. Allen G. P., Bryans J. T.: Molecular epizootiology, pathogenesis, and prophylaxis of equine herpesvirus-1 infections. Prog. Vet. Microbiol. Immunol. 1986, 2, 78-144.

3. Borchers K., Thein R., Sterner-Kock A.: Pathogenesis of equine herpesvirusassociated neurological disease: a revised explanation. Equine Vet. J. 2006, 38, 283-287.

4. Burns M., Valdiva $H .:$ Modelling the limit of detection in real-time quantitative PCR. Eur. Food. Res. Technol. 2008, 226, 1513-1524.

5. Cymerys J., Dzieciątkowski T., Golke A., Słońska A., Majewska A., Krzyżowska M., Bańbura M. W.: Primary cultures of murine neurons for studying herpes simplex virus 1 infection and its inhibition by antivirals. Acta Virol. 2013, 57, 339-345

6. Cymerys J., Dzieciątkowski T., Stońska A., Bierła J., Tucholska A., Chmielewska A., Golke A., Bańbura M. W.: Equine herpesvirus type 1 (EHV-1) replication in primary murine neurons culture. Pol. J. Vet. Sci. 2010, 13, 701-708.

7. Cymerys J., Słońska A., Brzezicka J., Tucholska A., Chmielewska A., Rola J., Malik P., Bańbura M. W.: Replication kinetics of neuropathogenic and nonneuropathogenic equine herpesvirus type $1(\mathrm{EHV}-1)$ strains in primary murine neurons and ED cell line. Pol. J. Vet. Sci. 2016, 19, 777-784.

8. Cymerys J., Słońska A., Godlewski M. M., Golke A., Tucholska A., Chmielewska A., Bańbura $M$. W.: Apoptotic and necrotic changes in cultured murine neurons infected with equid herpesvirus 1. Acta Virol. 2012, 56, 39-48.

9. Cymerys J., Słońska A., Tucholska A., Golke A., Chmielewska A., Bańbura $M . W$ : Influence of long-term equine herpesvirus type 1 (EHV-1) infection on primary murine neurons - the possible effects of the multiple passages of EHV-1 on its neurovirulence. Folia Microbiol. Praha 2017, [Epub ahead of print].

10. Drebert Z., Golke A., Cymerys J., Słońska A., Chmielewska A., Tucholska A., Bańbura $M$. W.: Equid herpesvirus type 1 (EHV-1) disrupts actin cytoskeleton during productive infection in equine leukocytes. Pol. J. Vet. Sci. 2015, 18, 107-112.
11. Goodman L. B., Loregian A., Perkins G. A., Nugent J., Buckles E. L., Mercorelli B., Kydd J. H., Palù G., Smith K. C., Osterrieder N., DavisPoynter N.: A point mutation in a herpesvirus polymerase determines neuropathogenicity. PLoS Pathog. 2007, 3, e160.

12. Iwasaki A., Medzhitov R.: Regulation of adaptive immunity by the innate immune system. Science 2010, 327, 291-295.

13. Kydd J. H., Townsend H. G., Hannant D.: The equine immune response to equine herpesvirus-1: the virus and its vaccines. Vet. Immunol. Immunopathol. 2006, 111, 15-30.

14. Liu Y., Li S.: A Cell Culture Model of Latent and Lytic Herpes Simplex Virus Type 1 Infection in Spiral Ganglion. ORL J. Otorhinolaryngol. Relat. Spec. 2015, 77, 141-149.

15. Lunn D. P., Davis-Poynter N., Flaminio M. J., Horohov D. W., Osterrieder K., Pusterla N., Townsend H. G.: Equine herpesvirus-1 consensus statement. J. Vet. Intern. Med. 2009, 23, 450-461.

16. Malik P., Pálfi V., Bálint A.: Development of a new primer-probe energy transfer method for the differentiation of neuropathogenic and non-neuropathogenic strains of equine herpesvirus-1. J. Virol. Met. 2010, 169, 425-427.

17. Miszczak D., Słońska A., Golke A., Cymerys J.: Herpesviruses survival strategies - latency and apoptosis. Postepy Hig. Med. Dosw. (Online) 2013, 67, 276-287.

18. Nugent J., Paillot R.: Equine herpesvirus myeloencephalopathy: unraveling the enigma. Vet. J. 2009, 180, 271-272.

19. Pusterla N., David Wilson W., Madigan J. E., Ferraro G. L.: Equineherpesvirus-1 myeloencephalopathy: a review of recent developments. Vet. J. 2009, 180, 279-289.

20. Stońska A., Cymerys J., Godlewski M. M., Dzieciątkowski T., Tucholska A., Chmielewska A., Golke A., Bańbura M. W.: Equine herpesvirus type 1 (EHV-1)induced rearrangements of actin filaments in productively infected primary murine neurons. Arch. Virol. 2014, 159, 1341-1349.

21. Stasiak K., Rola J., Ploszay G., Socha W. Żmudziński J. F.: Detection of the neuropathogenic variant of equine herpesvirus 1 associated with abortions in mares in Poland. BMC Vet. Res. 2015, 11, 102.

22. Wagner B., Wimer C., Freer H., Osterrieder N., Erb H. N.: Infection of peripheral blood mononuclear cells with neuropathogenic equine herpesvirus type-1 strain Ab4 reveals intact interferon- $\alpha$ induction and induces suppression of anti-inflammatory interleukin-10 responses in comparison to other viral strains. Vet. Immunol. Immunopathol. 2011, 143, 116-124.

Corresponding author: Anna Golke, DVM, PhD, Ciszewskiego 8, 02-786 Warsaw, Poland; e-mail: anna_golke@sggw.pl 